Arq. Bras. Med. Vet. Zootec., v.61, n.4, p.869-876, 2009

\title{
Identificação diferencial de Rhodococcus equi e Dietzia maris em bubalinos
}

[Differential identification of Rhodococcus equi and Dietzia maris in buffaloes]

\author{
L.R. Viana ${ }^{1}$, C.C. Krewer $^{2}$, G. Drescher ${ }^{2}$, A. Lazzari ${ }^{3}$, S.A. Botton ${ }^{1}$, M.M. Costa ${ }^{4}$, \\ E.L.S. Loreto ${ }^{1}$, A.C. Vargas $^{1 *}$ \\ ${ }^{1}$ Universidade Federal de Santa Maria \\ Av. Roraima, 1000 \\ 97105-900 - Santa Maria, RS \\ ${ }^{2}$ Universidade do Oeste de Santa Catarina - Chapecó, SC \\ ${ }^{3}$ Universidade Pioneira de Integração Social - Brasília, DF \\ ${ }^{4}$ Universidade Federal do Vale do São Francisco - Petrolina, PE
}

\begin{abstract}
RESUMO
Foram analisados 24 isolados bacterianos oriundos de leite e pele de búfalas (Bubalus bubalis), os quais foram previamente identificados como Rhodococcus equi com o auxílio de fenotipia concisa. Testes fenotípicos complementares e ferramentas moleculares foram utilizados com o objetivo de caracterizar esses isolados, bem como diferenciá-los de outros microrganismos intimamente relacionados. Observaram-se três fenótipos distintos, porém a identificação dos isolados foi inconclusiva. Apenas um dos isolados foi comprovado como sendo $R$. equi com a realização da PCR espécie-específica, sequenciamento e análise dos fragmentos de DNA. Os demais isolados só foram identificados pelo sequenciamento de fragmento do gene que codifica a região 16S do rRNA universal de bactérias, indicando tratar-se de Dietzia maris. O perfil de susceptibilidade aos antimicrobianos revelou maior resistência dos isolados de D. maris para oxacilina (96\%) e rifampicina (87\%). $\mathrm{O}$ isolado de $R$. equi apresentou resistência à amicacina, oxacilina, penicilina, rifampicina e tetraciclina. Alertase para o risco da incorreta identificação dos isolados baseados em testes fenotípicos concisos e para a necessidade de utilização de testes complementares para diferenciação entre $R$. equi e D. maris.
\end{abstract}

Palavras-chave: Bubalus bubalis, Rhodococcus equi, Dietzia maris, fenotipia, sequenciamento de DNA

\begin{abstract}
Twenty-four bacterial isolates from milk and skin of buffalo females (Bubalus bubalis), which previously had been identified as Rhodococcus equi by using a restricted number of phenotypical tests for bacterial characterization, were analyzed. The goal of this study was to perform the characterization of these isolates, as well as the differentiation of other microorganisms closely related by using additional phenotypical tests and molecular tools. Based on the phenotypical results, three different biotypes were obtained. However, the identification of the isolates was inconclusive. Only one of the isolates was confirmed as R. equi by the PCR specifically for this species, as well DNA sequencing and DNA fragment analysis. All the other isolates only could be precisely identified after the DNA sequencing, and they were characterized as Dietzia maris. The sensitivity profile to antimicrobials demonstrated the highest resistance of $\mathrm{D}$. maris to oxacillin and rifampin, $96 \%$ and $87 \%$, respectively. R. equi isolate, presented resistance to amikacin, oxacillin, penicillin, rifampin, and tetracycline. Thus, it is important to alert for the risk of the incorrect identification of the bacterial isolates by using diagnostic analysis based on phenotypical tests in order to differentiate R. equi and $\mathrm{D}$. maris, besides the necessity to use complementary tests for differentiation of these microorganisms.
\end{abstract}

Keywords: Bubalus bubalis, Rhodococcus equi, Dietzia maris, phenotypic test, DNA sequencing

Recebido em 24 de novembro de 2008

Aceito em 18 de junho de 2009

*Autor para correspondência (corresponding author)

E-mail: agueda.vargas@gmail.com 


\section{INTRODUÇÃO}

Rhodococcus equi é um microrganismo telúrico que se destaca como um patógeno oportunista, responsável por pneumonias e abscessos pulmonares tanto em animais como em humanos. É amplamente distribuído e está geralmente associado a pneumonias piogranulomatosas em equinos. Também pode estar associado a infecções em outras espécies como: bovinos, cervídeos, caprinos, ovinos, suínos, bubalinos, caninos, felinos e no homem (Prescott, 1991; Takai et al., 1993; Bell et al., 1996). Este microrganismo possui requerimentos nutricionais simples e pode ser isolado de uma grande variedade de fontes (Bell et al., 1996). Na última década, $R$. equi foi descrito em humanos como um importante agente infeccioso em pacientes imunocomprometidos (Byrne et al., 2001), podendo ser também agente de infecção em indivíduos imunocompetentes (Kedlaya et al., 2001).

Alguns actinomicetos corineformes, como $R$. equi, Dietzia sp., Gordonia sp. e Nocardia sp., apresentam características morfofisiológicas muito similares, o que pode dificultar a diferenciação entre os gêneros microbianos (Bizet et al., 1997). Muitos laboratórios de microbiologia utilizam essencialmente os testes fenotípicos para a identificação de $R$. equi, sendo mais comumente empregado o Christie, Atkins, Munch, Petersen Test (CAMP), que é considerado diferencial para a caracterização desse agente (Prescott et al., 1982; Carter e Cole, 1990).

Métodos como a reação da polimerase em cadeia (PCR) e o sequenciamento de DNA são amplamente utilizados como ferramentas auxiliares para diagnóstico e filogenia dos microrganismos com perfis fenotípicos similares (Macpherson e Muller, 2000). A PCR multiplex, que utiliza iniciadores da região $16 \mathrm{~S}$, para identificação do gênero e espécie de $R$. equi e para os genes plasmideais de virulência (vapA e $v a p \mathrm{~B}$ ), tem sido efetiva para a caracterização molecular e epidemiológica de isolados de $R$. equi em criações de equinos (Krewer et al., 2008). Para o gênero Dietzia, sem significado clínico marcante, os recursos moleculares são ainda escassos.
Tendo em vista a importância clínica emergente de $R$. equi e demais espécies relacionadas, tanto na medicina veterinária como na medicina humana, o presente trabalho teve por objetivo caracterizar fenotipicamente e por métodos moleculares os isolados bacterianos que apresentaram perfil fenotípico semelhante a $R$. equi, provenientes de amostras de pele e de leite de búfalas. Também foi avaliada a susceptibilidade desses agentes aos antimicrobianos comumente utilizados no tratamento de enfermidades causadas por $R$. equi.

\section{MATERIAL E MÉTODOS}

Utilizaram-se 24 isolados bacterianos oriundos de pele $(n=14)$ e do leite $(n=10)$ de búfalas da raça Murrah, que se encontravam em diferentes fases de lactação, pertencentes ao mesmo estabelecimento de criação. No laboratório de bacteriologia da Universidade Pioneira de Integração Social, Brasília, DF, esses isolados foram identificados como $R$. equi pelos testes fenotípicos de rotina (CAMP, produção de urease e redução de nitrato). Posteriormente, foram enviados ao laboratório de bacteriologia da UFSM, Santa Maria, RS, para caracterização molecular e avaliação de fatores de virulência de $R$. equi. Diante da discordância entre os resultados obtidos, foram empregados testes fenotípicos complementares e testes moleculares para identificação dos microrganismos isolados. Como controle das análises, foi utilizada a cepa padrão $\mathrm{ATCC}^{1} 33701 \mathrm{p}+$ de $R$. equi. Todas as bactérias empregadas no experimento encontravam-se liofilizadas e estocadas a $-20^{\circ} \mathrm{C}$, sendo suspensas em água destilada estéril antes de seu uso.

Os isolados foram semeados em ágar ${ }^{2}$ sangue ovino $5 \%$, incubados a $37^{\circ} \mathrm{C}$ por 48 horas. Após este período, as colônias foram submetidas a testes fenotípicos descritos por Quinn et al. (1994), Murray et al. (1995), Bizet et al. (1997), Pidoux et al. (2001) e Yumoto et al. (2002), os quais incluíram teste CAMP, avaliação de catalase e oxidase, redução de nitrato, produção de urease, utilização do ortho-nitrophenyl-b-Dgalactopyranoside (ONPG) e de carboidratos em

\footnotetext{
${ }^{1}$ American Type Culture Collection, Manassas, VA, EUA.

${ }^{2}$ HiMedia Laboratories Pvt. Ltda, Mumbai, India.
} 
meio líquido em base com vermelho de fenol (glicose, lactose, manitol, maltose, ribose, esculina, salicina, inulina) e em meio semissólido glicose oxidativa-fermentativa (GOF).

Para a avaliação de diferentes fenótipos, os resultados da caracterização bioquímica foram submetidos à taxonomia numérica pelo coeficiente de similaridade (Murray et al., 1995).

O método de difusão em ágar (Kirby-Bauer modificado) foi utilizado para avaliação da susceptibilidade dos isolados aos antimicrobianos (Bauer et al., 1966; Performance..., 1999) e como ferramenta auxiliar na sua identificação (Bizet et al., 1997). As drogas antimicrobianas ${ }^{3}$ testadas foram: amicacina $(30 \mu \mathrm{g})$, amoxicilina $(10 \mu \mathrm{g})$, ampicilina $(10 \mu \mathrm{g})$, azitromicina $(15 \mu \mathrm{g})$, cefalexina $(30 \mu \mathrm{g})$, cefoperazona $(75 \mu \mathrm{g})$, ciprofloxacina $(5 \mu \mathrm{g})$, eritromicina $(15 \mu \mathrm{g})$, gentamicina $(10 \mu \mathrm{g})$, norfloxacina $(10 \mu \mathrm{g})$, oxacilina $(1 \mu \mathrm{g})$, penicilina $\mathrm{G}$ (10UI), rifampicina $(5 \mu \mathrm{g})$ e tetraciclina $(30 \mu \mathrm{g})$. A seleção desses antimicrobianos baseou-se nos princípios ativos dos tratamentos comumente instituídos para animais com infecções por R. equi, segundo Murray et al. (1995) e Bizet et al. (1997).

Para as análises moleculares, os isolados foram cultivados em ágar $(\mathrm{BHI})^{4}$ e incubados em estufa microbiológica a $37^{\circ} \mathrm{C}$ por 48 horas. O DNA bacteriano foi extraído pelo método do brometo de cetiltrimetilamônio $\left(\mathrm{CTAB}^{5}\right)$ (Allers e Lichten, 2000), com algumas modificações sugeridas por Groff (2005).

A técnica de PCR multiplex para amplificação do fragmento do gene que codifica a região $16 \mathrm{~S}$ rRNA específica de $R$. equi e de fragmento dos genes plasmideais vap $\mathrm{A}$ e $v a p \mathrm{~B}$ seguiu as condições previamente descritas por Costa et al. (2002) e Oldfield et al. (2004). Alíquotas dos produtos amplificados $(7 \mu \mathrm{L})$ foram submetidas à eletroforese a $100 \mathrm{~V}$ por 30 minutos em um gel de agarose $1 \% \mathrm{e}$ corado com brometo de etídeo.

No sequenciamento de fragmentos de DNA dos isolados, um fragmento de aproximadamente $800 \mathrm{pb}$, correspondente a uma região do gene que codifica a subunidade $16 \mathrm{~S}$ do rRNA, foi amplificado por PCR a partir do DNA genômico dos 24 isolados. Para amplificação, foram

${ }^{3}$ Cefar diagnóstica Ltda, São Paulo, Brasil.

${ }^{4}$ Difco, Detroit, Michigan, USA.

${ }^{5}$ Sigma Chemical Co., St. Louis, Missouri, USA. empregados primers universais (Fredricks e Relman, 1998). As reações de PCR foram realizadas em um volume de $25 \mu \mathrm{L}$, empregando-se 50 ng de DNA, 20pmol de cada primer 6 , 1,5mM de $\mathrm{MgCl}_{2}, 50 \mu \mathrm{M}$ de cada nucleotídeo $\left(\mathrm{dNTP}^{6}\right)$ e $1 \mathrm{U}$ de Taq DNA polimerase ${ }^{6}$. A amplificação foi realizada por 40 ciclos de 30 seg a $94^{\circ} \mathrm{C}, 30 \mathrm{seg}$ a $48^{\circ} \mathrm{C}$ e $1 \mathrm{~min}$ a $72^{\circ} \mathrm{C}$, tendo uma extensão final de $7 \mathrm{~min}$ a $72^{\circ} \mathrm{C}$. Os fragmentos amplificados foram purificados com polietilenoglicol (PEG 8000 ${ }^{4}$ e submetidos ao sequenciamento automático em um equipamento MegaBace500 ${ }^{7}$. A reação de terminação de cadeia foi implementada com o uso do DYEnamic ET Dye Terminator Cycle Sequencing $\mathrm{Kit}^{6}$. As sequências obtidas foram analisadas quanto à qualidade dos nucleotídeos e similaridade, utilizando-se o programa STADEN (Staden et al., 2000), e comparadas com as sequências depositadas no GenBank (Benson et al., 2002), pelo programa Basic Local Alignment Tool for Nucleotides (BLASTn). Para um alto nível de qualidade das sequências, admitiram-se índices de confiança para cada nucleotídeo acima de $97 \%$ e níveis de identidade de sequência acima de $93 \%$, admitindose $\mathrm{E}=1 \mathrm{e}-100$.

\section{RESULTADOS}

Os 24 isolados demonstraram, em cultivo bacteriano em ágar sangue ovino $5 \%$ após $48 \mathrm{~h}$, crescimento de colônias mucoides com diferentes colorações (creme, laranja, salmão e rosa). A caracterização morfotintorial destas permitiu classificá-las como coco-bacilos pleomórficos, gram positivos. Todos os isolados apresentaram reação positiva para catalase e para o teste CAMP e negativa para oxidase, e utilização de GOF, inulina, manitol, lactose, salicina, ribose e esculina (Tab. 1).

Resultados variáveis foram observados em quatro (27\%) dos 15 testes fenotípicos avaliados (produção de urease, redução de nitrato, utilização de ONPG e utilização de glicose em meio líquido). Dentre os isolados, $23(96 \%)$ apresentaram variação apenas em uma das provas bioquímicas (redução de nitrato) e somente um demonstrou variação frente às análises da produção de urease, utilização de ONPG, utilização de glicose e redução de nitrato.

${ }^{6}$ Invitrogen, Life Technologies, Carlsbad, CA, EUA.

${ }^{7}$ Amershan Bioscience Corp., Piscataway, NJ, EUA. 
Tabela 1. Características bioquímicas e moleculares dos fenótipos caracterizados nos isolados bacterianos de búfalas

\begin{tabular}{|c|c|c|c|c|c|c|c|c|c|c|c|c|c|}
\hline \multirow[b]{2}{*}{ Isolado } & \multicolumn{9}{|c|}{ Característica bioquímica } & & \multicolumn{3}{|c|}{ Característica molecular } \\
\hline & 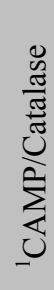 & 离 & 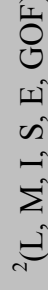 &  & $\underset{n}{\grave{Z}}$ & ঠৃ & $\begin{array}{l}\text { ஜ } \\
\text { ठ } \\
.0 \\
0\end{array}$ & 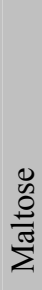 & 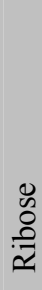 & 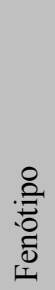 & 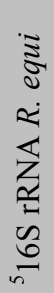 & 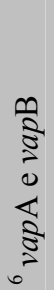 & Sequenciamento \\
\hline $\mathrm{T}+{ }^{7}$ & + & - & - & + & + & + & + & - & + & & + & + & R. equi \\
\hline $009 / 3 \mathrm{~L}$ & + & - & - & - & + & - & - & - & - & II & - & - & D. maris \\
\hline 009/4 L & + & - & - & - & + & - & - & - & - & II & - & - & D. maris \\
\hline 056/19 P & + & - & - & - & + & - & - & - & - & II & - & - & D. maris \\
\hline $056 / 10 \mathrm{P}$ & + & - & - & - & + & - & - & - & - & II & - & - & D. maris \\
\hline $061 / 53 \mathrm{P}$ & + & - & - & - & - & - & - & - & - & III & - & - & D. maris \\
\hline $068 / 82 \mathrm{~L}$ & + & - & - & - & + & - & - & - & - & II & - & - & D. maris \\
\hline 068/84 L & + & - & - & - & + & - & - & - & - & II & - & - & D. maris \\
\hline 096/37 P & + & - & - & - & - & - & - & - & - & III & - & - & D. maris \\
\hline $304 / 9 \mathrm{~L}$ & + & - & - & - & - & - & - & - & - & III & - & - & D. maris \\
\hline $304 / 11 \mathrm{P}$ & + & - & - & - & - & - & - & - & - & III & - & - & D. maris \\
\hline $304 / 21 \mathrm{P}$ & + & - & - & - & - & - & - & - & - & III & - & - & D. maris \\
\hline $304 / 31 \mathrm{P}$ & + & - & - & - & - & - & - & - & - & III & - & - & D. maris \\
\hline $336 / 81 \mathrm{~L}$ & + & - & - & - & + & - & - & - & - & II & - & - & D. maris \\
\hline $501 / 1 \mathrm{P}$ & + & - & - & + & + & + & + & - & - & I & + & - & R. equi \\
\hline $501 / 7 \mathrm{~L}$ & + & - & - & - & - & - & - & - & - & III & - & - & D. maris \\
\hline $501 / 24 \mathrm{~L}$ & + & - & - & - & - & - & - & - & - & III & - & - & D. maris \\
\hline $501 / 28 \mathrm{P}$ & + & - & - & - & + & - & - & - & - & II & - & - & D. maris \\
\hline $501 / 44 \mathrm{P}$ & + & - & - & - & - & - & - & - & - & III & - & - & D. maris \\
\hline $1035 / 13 \mathrm{P}$ & + & - & - & - & - & - & - & - & - & III & - & - & D. maris \\
\hline $1057 / 26 \mathrm{P}$ & + & - & - & - & - & - & - & - & - & III & - & - & D.maris \\
\hline $1057 / 32 \mathrm{P}$ & + & - & - & - & - & - & - & - & - & III & - & - & D. maris \\
\hline $1058 / 83 \mathrm{~L}$ & + & - & - & - & - & - & - & - & - & III & - & - & D. maris \\
\hline $1101 / 16 \mathrm{P}$ & + & - & - & - & + & - & - & - & - & II & - & - & D. maris \\
\hline $1101 / 25 \mathrm{~L}$ & + & - & - & - & - & - & - & - & - & III & - & - & D. maris \\
\hline
\end{tabular}

${ }^{1}$ CAMP: Christie, Atkins, Munch, Petersen test. ${ }^{2}$ Açúcares - L: lactose; M: manitol; I: inulina; S: salicina; E: esculina; $\mathrm{GOF}=$ glicose oxidativa-fermentativa. ${ }^{3} \mathrm{KNO}_{3}$ : teste de redução do nitrato. ${ }^{4} \mathrm{ONPG}$ : ortho-nitrophenyl-b-Dgalactopyranoside. ${ }^{5} \mathrm{PCR}$ do fragmento do gene que codifica para a região $16 \mathrm{~S}$ do rRNA de $R$. equi. ${ }^{6} \mathrm{PCR}$ de fragmentos dos genes plasmideais vapA e vapB. ${ }^{7} \mathrm{~T}+$ : amostra referência de Rhodococcus equi (ATCC $33701 \mathrm{p}+$ ). L: leite; P: pele.

Os resultados fenotípicos possibilitaram a classificação dos isolados em três fenótipos, sendo um isolado (4\%) pertencente ao fenótipo I, nove $(38 \%)$ ao fenótipo II e $14(58 \%)$ ao fenótipo III. A análise de similaridade das características fenotípicas dos 24 isolados estudados com os padrões de $R$. equi e actinomicetos assemelhados relacionou o isolado do fenótipo I com $93 \%$ de similaridade a Rhodococcus equi e a Dietzia maris. O fenótipo
II apresentou $100 \%$ de identidade com $D$. maris e $80 \%$ com $R$. equi. Já o fenótipo III apresentou $93 \%$ e $80 \%$ de similaridade com $D$. maris e com $R$. equi, respectivamente. Também se observou, que em $71 \%(5 / 7)$ dos isolados oriundos das diferentes coletas do mesmo animal, os fenótipos foram equivalentes.

No teste de susceptibilidade aos antimicrobianos, 23 isolados (fenótipos II e III) foram sensíveis à 
amicacina, amoxicilina, ampicilina, azitromicina, cefalexina, cefoperazona, eritromicina, gentamicina, norfloxacin e tetraciclina. Resistência foi observada à oxacilina $(96 \%)$ e à rifampicina $(87 \%)$. Sensibilidade intermediária foi encontrada para ciprofloxacina e penicilina em $8,6 \%$ dos isolados. O isolado do fenótipo I apresentou perfil de susceptibilidade aos antimicrobianos diferenciado, sendo resistente à amicacina, oxacilina, penicilina, rifampicina e tetraciclina, sensibilidade intermediária à cefalexina e sensível aos demais princípios testados.

Vinte e três isolados foram negativos para a amplificação do fragmento do gene que codifica a região 16S do rRNA de $R$. equi (fenótipos II e III), e nenhum dos isolados apresentou os genes vapA e vapB. Dessa forma, a técnica de PCR identificou um (4\%) isolado (fenótipo I) como $R$. equi. $\mathrm{O}$ sequenciamento $\mathrm{e}$ a análise de fragmentos da região conservada do gene $16 \mathrm{~S}$ rRNA determinaram que os isolados não identificados pela PCR para $R$. equi, pertenciam ao gênero Dietzia.

Uma vez que a qualidade de sequências geradas pelo sequenciamento automático apresenta heterogeneidade, primeiramente foram verificados o tamanho e a qualidade de sequência necessários para um correto emprego na identificação. Determinou-se que o tamanho mínimo de sequência a ser empregada corresponde a $250 \mathrm{pb}$ com índice Phred acima de 20. Sequências com qualidade inferior a estas foram descartadas. Foi possível identificar 23 (96\%) dos isolados estudados como D. maris. Os fragmentos de DNA analisados apresentaram valores de similaridade e identidade com as sequências já existentes no GenBank, que variaram de 93 a $99 \%$, com $\mathrm{E}=1 \mathrm{e}-100$. O isolado que apresentou resultado positivo para $R$. equi pela técnica de PCR foi confirmado também pelo sequenciamento do DNA.

\section{DISCUSSÃO}

Historicamente, a classificação das bactérias é baseada na similaridade das características fenotípicas como morfologia, cultivo, nutrição, bioquímica, metabolismo, patogenicidade, sorologia e ecologia. Os resultados morfofisiológicos dos 24 isolados avaliados neste estudo evidenciaram características muito similares, e perfis compatíveis com $R$. equi e com D. maris, conforme descrições de Carter e Cole (1990), Murray et al. (1995) e Bizet et al. (1997). Segundo Lasker et al. (1992) e Bizet et al. (1997), o maior empecilho à classificação dos actinomicetos está associado à variabilidade e à falta de características fenotípicas diferenciais, o que pode explicar a identificação inicial dos isolados como $R$. equi mediante utilização de uma série bioquímica concisa (CAMP, produção de urease e redução de nitrato), comumente utilizada em laboratórios de diagnóstico. As reações positivas obtidas em todos os isolados no teste CAMP, até então considerado como prova definitiva para a identificação de $R$. equi segundo Prescott et al. (1982) e Finger (1996), confirmam os achados de Lasker et al. (1992) e indicam a fragilidade dessa prova para a identificação de $R$. equi, pois resultados positivos, até então não descritos, também foram encontrados nos isolados caracterizados como D. maris.

No presente trabalho, os distintos fenótipos obtidos evidenciaram a variabilidade fenotípica dos isolados dentro das espécies. A utilização da ribose apenas pela cepa controle de $R$. equi (ATCC 33701p+) é discordante da observação de Bizet et al. (1997), que relataram o uso desse açúcar por $R$. equi, mas não por D. maris. O emprego da glicose, também, não se mostrou um teste discriminatório apesar de todos os isolados apresentarem resultados negativos, pois, segundo Bizet et al. (1997), esta é uma característica variável. O teste do ONPG foi o único que demonstrou capacidade discriminatória entre $R$. equi e D. maris, semelhante às sugestões de Holt et al. (1994) e Bizet et al. (1997), que mostraram a necessidade de inclusão desse teste no diagnóstico laboratorial. No entanto, estudos recentes, realizados pelo grupo que realizou esta pesquisa, evidenciaram dois isolados de $R$. equi provenientes de javalis que não utilizaram o ONPG (dados não publicados). Esta observação ratifica a proposta de Young (2001) de que a utilização de apenas uma prova na diferenciação entre dois gêneros bacterianos não é satisfatória para a identificação final. Conforme Lasker et al. (1992), seriam necessários de 107 a 129 testes bioquímicos para a identificação bioquímica eficiente de $R$. equi. Todavia, Maraschin (2007) afirmou que, apesar do emprego de vastas séries bioquímicas, a identificação fenotípica de alguns gêneros permanecerá complexa, e os 
microrganismos só poderão ser identificados com o auxílio de técnicas complementares.

Com o emprego de testes fenotípicos adicionais, foi possível visualizar variações nos resultados bioquímicos das bactérias estudadas, as quais puderam ser comprovadas, pelos distintos perfis fenotípicos obtidos e apresentados na Tab. 1 .

A resistência à oxacilina e à rifampicina, observada nos isolados de D. maris, difere dos resultados obtidos por Bizet et al. (1997), que relataram sensibilidade de cepas de D. maris frente à rifampicina e à oxacilina, não sendo este teste uma ferramenta útil na identificação desses microrganismos corineformes. Observou-se também divergência no perfil de susceptibilidade do isolado identificado como $R$. equi em relação aos descritos por Murray et al. (1995). Estas autores verificaram sensibilidade das cepas de $R$. equi à amicacina, oxacilina, rifampicina $\mathrm{e}$ tetraciclina.

Os resultados negativos para a amplificação dos fragmentos dos genes vapA e vap B evidenciaram ausência de fatores de virulência no isolado de $R$. equi que normalmente estão associados a plasmídeos, os quais conferem aos isolados diferentes níveis de patogenicidade. Este achado sugere sua origem ambiental, entretanto isolados avirulentos têm sido associados a enfermidades no homem e nos animais (Takai et al., 1995; Weinstock e Brown, 2002). Uma vez que os búfalos vivem em ambientes onde há grande disseminação de microrganismos telúricos, admite-se a possibilidade da colonização da glândula mamária desses animais por bactérias dos gêneros Dietzia e Rhodococcus. Embora neste trabalho não tenha sido evidenciada a ocorrência de mastite, alerta-se para a necessidade de mais estudos para avaliação do potencial patogênico desses microrganismos. Conforme Pidoux et al. (2001) e Reyes et al. (2006), D. maris e R. equi já foram encontrados em infecções de pacientes com o sistema imune debilitado (Pidoux et al., 2001; Weinstock e Brown, 2002).

A análise das sequências da região conservada do gene que codifica o $16 \mathrm{~S}$ rRNA permitiu classificar os isolados não identificados pela PCR como pertencentes ao gênero Dietzia. A técnica de análise de sequências codificantes do 16S rRNA vem sendo amplamente utilizada no diagnóstico de bactérias, cuja identificação bioquímica não é precisa (Pidoux et al., 2001; Reyes et al., 2006). Contudo, essa técnica pode trazer erros, principalmente tendo em vista a troca de material genético entre microrganismos, bem como a reduzida qualidade nas sequências obtidas (Young, 2001). Para reduzir esses problemas, as sequências obtidas no presente estudo foram submetidas à análise de qualidade utilizando-se o pacote Staden (Staden et al., 2000).

O emprego de métodos fenotípicos e moleculares para identificação de bactérias é amplamente descrito na literatura (Soedermanto et al., 1998; Costa et al., 2004). Bactérias corineformes pertencem ao grupo de microrganismos cujos métodos de diagnóstico convencionais, baseados exclusivamente nas características fenotípicas, são inconclusivos (Bizet et al., 1997). Dessa forma, tornam-se necessárias outras metodologias complementares, como a PCR e o sequenciamento de DNA (Bizet et al., 1997; Pidoux et al., 2001). Essas metodologias, entretanto, apresentam desvantagens relacionadas ao seu custo e aos critérios de interpretação. Neste estudo, a análise de regiões conservadas do gene $16 \mathrm{~S}$ rRNA permitiu a definitiva classificação dos organismos, auxiliando, dessa forma, a identificação fenotípica. Apesar da utilização de testes fenotípicos complementares, foram observadas variações nos resultados obtidos e insatisfatório discernimento. Alerta-se, ainda, para o risco da incorreta identificação dos isolados, quando da utilização de testes diagnósticos fenotípicos diferenciais entre $R$. equi e Dietzia sp. Os resultados deste trabalho assemelham-se às descrições de Young (2001), o qual afirma que os métodos de taxonomia bacteriana devem passar por reformulações, substituindo a corrente monofásica (baseada em uma ou poucas características) e adotando a visão polifásica, em que vários critérios fenotípicos, genéticos $\mathrm{e}$ evolutivos devem ser combinados para a correta identificação dos microrganismos.

\section{CONCLUSÕES}

Dietzia maris e Rhodococcus equi, presentes na microbiota da pele e no leite de búfalas, possuem características morfofisiológicas muito semelhantes, sendo os testes fenotípicos rotineiramente utilizados insuficientes para a 
identificação e a diferenciação de gênero. $D$. maris apresenta teste CAMP positivo, não sendo essa prova útil na distinção com $R$. equi. Testes de caracterização molecular, como a PCR e o sequenciamento de DNA, são importantes ferramentas para complementar a caracterização microbiana e devem ser utilizados quando os testes fenotípicos, para a classificação bacteriana, são escassos.

\section{REFERÊNCIAS BIBLIOGRÁFICAS}

ALLERS, T.; LICHTEN, M. A method for preparing genomic DNA that restrains branch migration of Holliday junctions. Nucleic Acids Res., v.28, pE6-E6, 2000.

BAUER, A.W.; KIRBY, W.M.M.; SHERRIS, J.C. et al. Antibiotic susceptibility testing by a standardized single disk method. Am. J. Clin. Pathol., v.45, p.493-496, 1966.

BELL, K.S.; CHRISTOFI, N.; AW, D.W.J. Identification of $R$. equi using the polymerase chain reaction. Lett. Appl. Microbiol., v.23, p.7274, 1996.

BENSON, D.A.; KARSCH-MIZRACHI, I.; LIPMAN, D.J. et al. Genbank. Nucleic Acid Res., v.30, p.17-20, 2002.

BIZET, C.; BARREU, C.; HARMANT, C. et al. A. Identification of Rhodococcus, Gordona and Dietzia species using carbon source utilization tests ("biotype-100" strips). Res. Microbiol., v.148, p.799-809, 1997.

BYRNE, B.A.; PRESCOTT, J.F.; PALMER, G.H. et al. Virulence plasmid of Rhodococcus equi contains inducible gene family encoding secreted proteins. Infect. Immun., v.69, p.650656, 2001.

CARTER, G.R.; COLE, J. R. Jr. Actinomyces, Nocardia, Streptomyces, Dermatophilus, and Rhodococcus. In: PRESCOTT, J.F. Diagnostic procedures in veterinary and mycology. 5.ed. New York: Academic, 1990. p.271-286.

COSTA, M.M.; KLEIN, C.S.; BALESTRIN, R. et al. Evaluation of PCR based on gene apxIVA associated whith $16 \mathrm{~S}$ rDNA sequencing for the identification of Actinobacillus pleuropneumonie and related species. Curr. Microbiol., v.48, p.189-195, 2004.

COSTA, M.M.; KREWER, C.C.; SILVA, M.S. et al. Utilização da técnica de PCR multiplex para caracterização molecular de isolados de Rhodococcus equi de haras da região de Bagé, RS, Brasil. In: REUNIÃO DE GENÉTICA DE MICRORGANISMOS, 23., 2002, Pirenópolis. Anais..., Pirenópolis: [s.n.], 2002. p.61. (Resumo).

FINGER, G.P. Caracterização de amostras de Rhodococcus equi de equinos no Rio Grande do Sul. 98f. Dissertação (Mestrado) - Universidade Federal do Rio Grande do Sul, Porto Alegre.

FREDRICKS, D.N.; RELMAN D. A. Sequencing of DNA bacteria by universal 16S rDNA PCR. J. Clin. Microbiol., v.36, p.28102816, 1998.

GROFF, A.C.M. PCR para o diagnóstico da Campilobacteriose genital bovina. 2005. 46f. Dissertação (Mestrado) - Universidade Federal de Santa Maria, Santa Maria.

HOLT, J.G., KRIEG, N.R., SNEATH, P.H.A. et al. Bergey's manual of determinative bacteriology. 9.ed. Baltimore: Willians \& Wilkins, 1994. 787p.

KEDLAYA, I.; ING, M.B.; WONG, S.S. $R$. equi infections in immunocompetent hosts: case report and review. Clin. Infect. Dis., v.32, p.3947, 2001.

KREWER C.C.; SPRICIGO, D.A.; BOTTON, S.A. et al. Molecular characterization of Rhodococcus equi isolates of horse breeding farms from an endemic region in South of Brazil by multiplex PCR. Braz. J. Microbiol., v.39, p.188-193, 2008.

LASKER, B.A.; BROWN, J.M.; McNEIL, M.M. Identification and epidemiological typing of clinical and environmental isolates of the genus $R$. equi with use of a digoxigenin-labeled rDNA gene probe. Clin. Infect. Dis., v.15, p.223-233, 1992.

MACPHERSON, M.J.; MULLER, S.G. PCR: The basics. New York: Springer-Verlag, 2000. $276 \mathrm{p}$.

MARASCHIN, M.M. Identificação de bacilos Gram positivos aeróbicos isolados de espécimes clínicos em um hospital escola. 86f. 2007. Dissertação (Mestrado) - Universidade Federal de Santa Maria, Santa Maria.

MURRAY, P.R. BARON, E.J.; PFALLER, M.A. et al. Manual of clinical microbiology. 6.ed. Washington, DC: ASM Press, 1995. p.379-399. 
OLDFIELD, C.; BONELLA, H.; REINVICK, L. et al. Rapid determination of vapA/vapB genotype in Rhodococcus equi using a differential polymerase chain reaction method. Antonie Van Leeuwenhoek, v.85, p.317-326, 2004.

PERFORMANCE standards for antimicrobial susceptibility testing: Ninth informacional supplement. Wayne, PA: Clinical and Laboratory Standards Institute, NCCLS, 1999. (M100-S9, v.19, n.1).

PIDOUX, O.; ARGENSON, J.N.; JACOMO, V. et al. Molecular identification of a Dietzia maris hip prosthesis infection isolate. J. Clin. Microbiol., v.39, p.2634-2636, 2001.

PRESCOTT, J.F. R. equi: an animal and human pathogen. Clin. Microbiol. Rev., v.4, p.20-34, 1991.

PRESCOTT, J.F.; LASTRA, M.; BARKSDALE, L. Equi factors in the identification of Corynebacterium equi Magnusson. J. Clin. Microbiol., v.16, p.988-990, 1982.

QUINN, P.J.; CARTER, M.E.; MARKER, B. et al. Clinical veterinary medicine. London: Mosby-Year, 1994. 648p.

REYES, G.; NAVARRO, J.L.; GAMALLO, C. et al. Type A aortic dissection associated with Dietzia maris. Interact. Cardiovasc. Thorac. Surg., v.5, p.666-668, 2006.
SOEDERMANTO, I.; ZHICAI, W.; SETYAMAHANANI, A. et al. Pheno-and genotyping of $R$. equi isolated from faeces of healthy horses and cattle. Res. Vet. Sci., v.64, p.181-185, 1998.

STADEN, R.; BEAL, K.F.; BONFIELD, J.K. The Staden Package, 1998. Methods Mol. Biol., v.132, p.115-130, 2000.

TAKAI, S.; ANZAI, T.; SASAKI, Y. e al. Virulence of Rhodococcus equi isolated from lesions of infected foals. Bull. Equine Res. Inst., n.30, p.9-14, 1993.

TAKAI, S.; IKEDA, T.; SASAKI, Y. et al. Identification of virulent Rhodococcus equi by amplification of gene coding 15-to 17-Kilodalton antigens. J. Clin. Microbiol., v.33, p.1624-1627, 1995.

WEINSTOCK, D.M.; BROWN, A.E. Rhodococcus equi: an emerging pathogen. Clin. Infect. Dis., v.15, p.1379-1385, 2002.

YOUNG, J.M. Implications of alternative classications and horizontal gene transfer for bacterial taxonomy. Int. J. Syst. Evol. Microbiol., v.51, p.945-953, 2001.

YUMOTO, I.; NAKAMURA, A.; IWATA, H. et al. Dietzia psychralcaliphila sp. nov., a novel, facultatively psychrophilic alkaliphile that grows on hydrocarbons. Int. J. Syst. Evol. Microbiol., v.52, p.85-95, 2002. 